\title{
Thinking Atopic Dermatitis Treatment Differently: Specific Immunotherapy as an Option
}

\author{
Massimo Milani \\ ALK Abellò Medical Department, \\ Lainate, Milan \\ Italy
}

\section{Introduction}

Atopic Dermatitis (AD) is a common inflammatory itching skin disease ${ }^{1}$. This skin disorder affects a large number of children and adults². Epidemiological studies show that up to $25 \%$ of children and up to $3 \%$ of adult are affected worldwide ${ }^{3}$. Several studies in addition suggest an increasing prevalence of AD. The clinical picture of AD is dominated by chronic eczematous skin lesions in typical localizations ${ }^{4}$. In infants and small children, the rash is often present on the skin around the knees and elbows and the cheeks ${ }^{5}$. In teenagers and adults, the rash is often present in the creases of the wrists, elbows, knees or ankles, and on the face or neck. Symptoms commonly could vary from person to person. The most common symptoms are dry, itchy skin and rashes on the face, inside the elbows and behind the knees, and on the hands and feet ${ }^{6}$. Itching is the most relevant and common symptom of atopic dermatitis. Scratching and rubbing in response to itching irritates the skin, increases inflammation, and actually increases itchiness. Itching is a particular problem during sleep when conscious control of scratching is lost. The appearance of the skin that is affected by atopic dermatitis depends on the amount of scratching and the presence of secondary skin infections. The skin may be red and scaly, be thick and leathery, contain small raised bumps, or leak fluid and become crusty and infected. These features can also be found in people who do not have atopic dermatitis or who have other types of skin disorders. Atopic dermatitis may also affect the skin around the eyes, the eyelids, and the eyebrows and lashes. Scratching and rubbing the eye area can cause the skin to redden and swell. Some people with atopic dermatitis develop an extra fold of skin under their eyes. Patchy loss of eyebrows and eyelashes may also result from scratching or rubbing. In addition clinically unaffected skin in AD is not normal. It is frequently dry and has a greater irritant skin response than normal healthy skin?. Microscopic studies reveal a sparse perivascular T-cell infiltrate in unaffected AD skin that is not seen in normal healthy skin 8 .

There is a marked infiltration of CD41 activated memory T cells in acute AD ${ }^{9}$. Antigenpresenting cells (eg, Langerhans cells inflammatory dendritic epidermal cells and macrophages) in lesional and, to a lesser extent, in nonlesional skin bear IgE molecules ${ }^{10}$. 
Mast cell degranulation can be observed. Macrophages dominate the dermal mononuclear cell infiltrate. Eosinophils also contribute to the inflammatory response, and $\mathrm{T}$ cells remain present, although in smaller numbers than seen in acute $\mathrm{AD}^{11}$. Chronic $\mathrm{AD}$ skin lesions undergo tissue remodeling caused by chronic inflammation. These skin lesions are associated with thickened plaques with increased skin markings (lichenification), increased collagen deposition in the dermis, and dry fibrotic papules ${ }^{12}$. AD is characterized by dry skin, even involving nonlesional skin and increased transepidermal water loss ${ }^{13}$. In particular, ceramides serve as the major water-retaining molecules in the extracellular space of the cornified envelope, and the barrier function of these complex structures is provided by a matrix of structural proteins, which are bound to ceramides ${ }^{14}$. A reduced content of ceramides has been reported in the cornified envelope of both lesional and nonlesional skin in patients with $\mathrm{AD}$. Changes in stratum corneum $\mathrm{pH}$ levels have been found in patients with $\mathrm{AD}$ and might impair lipid metabolism in the skin. Overexpression of stratum corneum chymotryptic enzyme is also likely to contribute to the breakdown of the AD epidermal barrier ${ }^{15}$.

Atopic dermatitis is very common: it affects males and females and accounts for 10 to 20 percent of all visits to dermatologists ${ }^{16}$. Although atopic dermatitis may occur at any age, it most often begins in infancy and childhood. Scientists estimate that 65 percent of patients develop symptoms in the first year of life, and 90 percent develop symptoms before the age of 517. The cause of atopic dermatitis is not known, but the disease seems to result from a combination of genetic and environmental factors ${ }^{18}$. Children are more likely to develop this disorder if one or both parents have had it or have had other allergic conditions like asthma or allergic rhinitis ${ }^{19}$. While some people outgrow skin symptoms, approximately threefourths of children with atopic dermatitis go on to develop hay fever or asthma ${ }^{20}$. Environmental factors can bring on symptoms of atopic dermatitis at any time in individuals who have inherited the atopic disease trait ${ }^{21}$.

\section{Atopic dermatitis and immune system: $A D$ as an allergic disease}

Atopic dermatitis is associated with malfunction of the body's immune system: the system that recognizes and helps fight bacteria and viruses that invade the body ${ }^{22}$. Scientists have found that people with atopic dermatitis have a low level of Interferon gamma (INF- $\gamma$ ) a cytokine (a protein) that is essential to the healthy function of the body's immune system and a high level of other cytokines such as IL-4 and IL-5 and IL-13 that lead to allergic reactions. The immune system can become misguided and create inflammation in the skin even in the absence of a major infection ${ }^{23}$. This can be viewed as a form of autoimmunity, where a body reacts against its own tissues. $\mathrm{AD}$ is also an important component of the atopic diathesis. $\mathrm{AD}$ frequently is associated with allergic respiratory disease and often is the first manifestation of allergic disease ${ }^{24}$. Patients suffering from AD will develop allergic rhinitis and asthma. The onset of AD generally occurs during the first 6 months of life. In adults with AD only $17 \%$ had onset after adolescence ${ }^{25}$. AD may arise from disregulation of $\mathrm{IgE}$ and $\mathrm{T}$ cell mediated hypersensitivity reactions ${ }^{26}$. Atopy is significantly associated with manifestation and severity of $\mathrm{AD}$, especially in children. Exposure to aeroallergen (mites and pollen) has been shown to increase the risk factors for $\mathrm{AD}$ and $\mathrm{AD}$ severity ${ }^{27}$. Children with $\mathrm{AD}$ are at a high risk of allergic asthma and allergic rhinitis. Furthermore, aeroallergens are a trigger for exacerbations in adult AD. In about $80 \%$ of adult patients with 
$\mathrm{AD}$, the disease is associated with increased serum IgE levels, sensitization against aeroallergens and concomitant allergic rhinitis and asthma. Patients with AD can have very high serum IgE levels, often more than $10,000 \mathrm{IU} / \mathrm{mL}$. It is important to note that specific IgE against allergens, whether measured in vivo by using SPTs or by using in vitro assays, does not equate to clinical disease or define clinical relevance in a given patient. In general, properly done SPTs to food allergens have a high negative predictive value, but the positive predictive value is only slightly higher than $50 \%$ for all patients. The inflammatory process in the skin initiates with the allergen uptake by epidermal dendritic cells which share in their surface the IgE-receptor. These cells, after the contact with the allergens, start the homing process of $\mathrm{T}$ cells. This process plays a central role for the inflammatory damage of skin $^{28}$. Up to $80 \%$ of patients suffering from AD are sensitised against different aero and food allergens. This sensitisation is reflected by an increased total and allergen-specific IgE and/or by a positive Skin prick test ${ }^{29}$.

\subsection{AD as an allergic disease: The role of allergens sensitization}

Sensitization to inhalant allergens is often seen in patients with $\mathrm{AD}^{30}$. Allergens can exacerbate AD either by means of inhalation, direct contact with the skin, or ingestion. Sensitization can be detected by means of SPTs (if the skin is free from eczema) or by measurement of specific IgE antibodies. In addition, Atopy Patch Test can be used to assess the response in the skin. Most important allergens include dust mite, animal dander, and pollen confirmed by clinical trials and avoidance measures ${ }^{31}$. The role of dust mite allergen exposure is supported by patch tests, avoidance studies, and the very high titers of IgE antibodies to mite proteins in a large proportion of adults, as well as children older than 7 years with AD. The positive effect of house dust mite avoidance with special encasings has been shown in various studies ${ }^{32}$. Allergen avoidance however has limited efficacy in HMD allergic patients.

\subsection{Traditional therapeutic approach of $A D$}

Basic therapy of $\mathrm{AD}$ should comprise optimal skin care, addressing the skin barrier defect with the regular use of moisturizing and emollient topical products and skin hydration 33 . An additional relevant therapeutic approach is the identification and the avoidance of both specific and nonspecific trigger factors. Non specific irritants include clothing made from occluding or irritating synthetic or wool material. A key feature of AD is severe dryness of the skin caused by a dysfunction of the skin barrier with increased transepidermal water loss. This is typically accompanied by intense itch and inflammation. The regular use of emollients is important for addressing this problem, and together with skin hydration, it represents the mainstay of the general management of $\mathrm{AD}^{34}$. Emollients should be applied continuously, even if no actual inflammatory skin lesions are obvious. Corticosteroid creams and ointments have been used for many years to treat atopic dermatitis and other autoimmune diseases affecting the skin $^{35}$. Sometimes over-the-counter preparations are used, but in many cases the doctor will prescribe a stronger corticosteroid cream or ointment. The side effects of uncontrolled topical steroid use, particularly on delicate skin areas, are well documented, and therefore topical steroid preparations should be applied no more than twice daily as short-term therapy for acute eczematous lesions ${ }^{36}$. Only mild to moderately potent preparations should be used on genital, facial, or intertriginous skin areas. New medications known as immuno modulators have been developed that help control 
inflammation and reduce immune system reactions when applied to the skin. Examples of these medications are tacrolimus ointment and pimecrolimus cream ${ }^{37}$. They can be used in patients older than 2 years of age and have few side effects (burning or itching the first few days of application). They not only reduce flares, but also maintain skin texture and reduce the need for long-term use of corticosteroids. However corticosteroids and immunomodulators are not eziologic treatments of AD. These approaches in fact are mostly limited to control symptoms and suppress inflammatory reactions but they are not causal treatments of this skin condition.

\subsection{Thinking AD treatment approach differently: The specific allergen immunotherapy as an option}

Several anecdotal and case reports suggest clinical benefit from allergen-specific desensitization (specific immunotherapy [SIT]) in $\mathrm{AD}^{38}$. SIT is effective in the management of allergic asthma, allergic rhinitis/conjunctivitis, and stinging insect hypersensitivity ${ }^{39}$. There is some evidence it might be effective in the treatment of atopic dermatitis in patients with aeroallergen sensitivity. At least 12 placebo controlled trials have been conducted to evaluate the efficacy of SIT in AD patients ${ }^{40}$. A total of 9 trials (75\%) reported significant positive effect of SIT in comparison with placebo. More recently, one double-blind controlled trial in children with dust mite allergy and AD failed to show efficacy of SIT compared with placebo after 8 months of therapy ${ }^{41}$. However, treatment for an additional 6 months resulted in clinical improvement, suggesting that prolonged desensitization might be more effective than placebo. A more recent multicenter, randomized, blinded, dose-response trial with house dust mite SIT in 89 adults with chronic AD sensitized to dust mite showed that the SCORAD score decreased in the 3 dose groups in a dose-dependent manner and was significantly lower in the 2 high-dose groups compared with the low-dose group after 1 year of SIT ${ }^{42}$. The use of topical corticosteroids was also significantly reduced with higher doses, suggesting that SIT might be useful for patients with AD sensitized to house dust mite. This study demonstrated that adult atopic patients with severe form of AD could benefit from SIT. Children with AD with or without respiratory allergies or asthma have also been treated with allergen-specific oral desensitization (SLIT), with $69 \%$ of the group without respiratory allergies-asthma versus $74 \%$ of the group with respiratory allergies-asthma showing complete resolution of their skin disease after 24 months of therapy. To date, specific immunotherapy (SIT) is not an established therapeutic approach for the treatment of AD even if the recent Immunotherapy Practice Parameter states that AD could be a clinical indication for SIT. Some controlled trials have failed to show clinical efficacy of SIT in the treatment of AD. However, SIT with house dust mite (HDM) subcutaneous preparation has been recently shown, in a randomized double-blind trial, to improve eczema in patients with AD.

\subsection{Clinical efficacy of sublingual immunotherapy in AD}

In comparison with subcutaneous SIT, sublingual immunotherapy (SLIT) is considered a more convenient and safer approach for the treatment of some forms of allergies. So far, there is few and conflicting data regarding the efficacy and safety of Specific Sublingual Immunotherapy (SLIT) in patients with AD. In a randomised double blind trial a total of 
56 children with AD were treated with SLIT HDM allergen extracts or the corresponding placebo for 18 months. Significant improvement of SCORAD (Scoring Atopic Dermatitis) in the active group was observed as soon as 9 months of treatment. Lower use of rescue medication in the active group was observed after 18 months ${ }^{43}$. We have conducted a multicenter trial evaluating the efficacy of SLIT in $96 \mathrm{AD}$ patients showing that this therapeutic option is efficacious and safe ${ }^{44}$. More in details, 96 subjects (58 women and 38 men; between 18 and 60 years of age) with AD and IgE-proved HDM sensitivity (Class $>2$ ) were enrolled in the trial after their informed consent. Exclusion criteria were severe asthma and treatment with systemic or high potent topical corticosteroids or immunosuppressant agents. Patients were treated with SLIT for at least 12 months. SCORAD was evaluated at baseline and after 12 months of treatment. Results: baseline SCORAD value (mean \pm SD) was $43.3 \pm 13.7$ (range: 18-84). After 1 year of SLIT, SCORAD value was reduced to $23.7 \pm 13.3$ (range: $0-65$; $p=0.0001$; unpaired T-Test vs baseline). This was a $46 \%$ reduction in SCORAD in comparison with baseline time. A significant improvement, defined as a SCORAD reduction of $>30 \%$, was observed in 57 out of 96 patients $(59.2 \%)$. In 6 patients $(5.9 \%)$ the SCORAD value did not change at the end of the observation period. In 33 patients (34.9\%) the SCORAD reduction after SLIT was $\leq 30 \%$ in comparison with baseline (Figure 1). Specific-IgE serum levels were significantly

\section{Evolution of SCORAD}

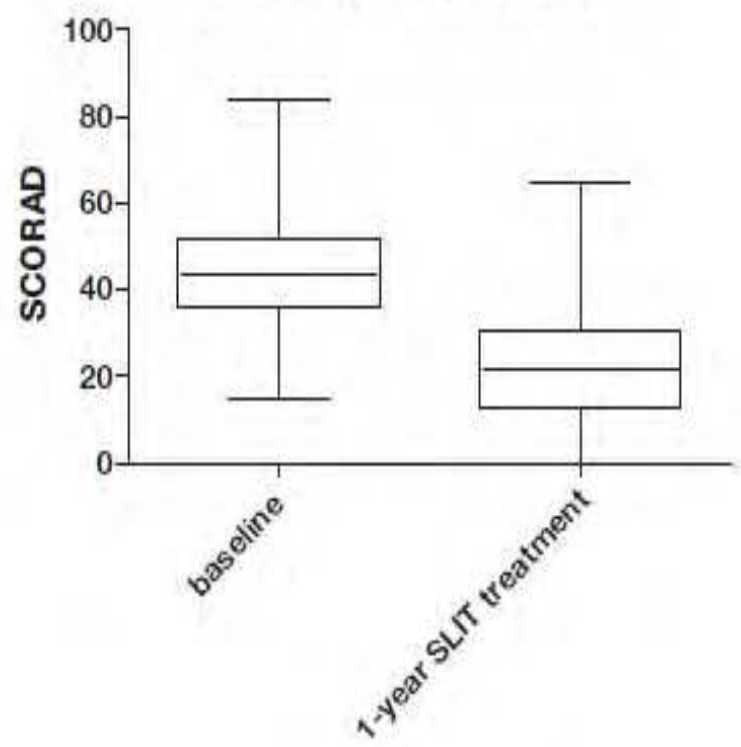

Fig. 1. Evolution of SCORAD index at baseline and after1 year of SLIT treatment $(n=96) ;(p$ $=0.0001$ paired $\mathrm{t}$-test)

$(\mathrm{p}=0.001)$ reduced after SLIT (Figure 2). No severe adverse events were observed during the trial. In this trial the SLIT with HDM extracts in patients with mild-moderate AD was effective in reducing the SCORAD after 1 year of SLIT treatment. In addition, the 
treatment was very well tolerated. Treatment with SLIT, furthermore, has allowed a gradual and relevant reduction of concomitant therapies with corticosteroids and immunosuppressants. SLIT can modulate the immuno-system in patients with AD and HDM sensitivity. In conclusion the data available from different trials suggest that SIT (both SCIT and SLIT) could be a relevant therapeutic option in the management of AD.

\section{Specific anti HDM IgE}

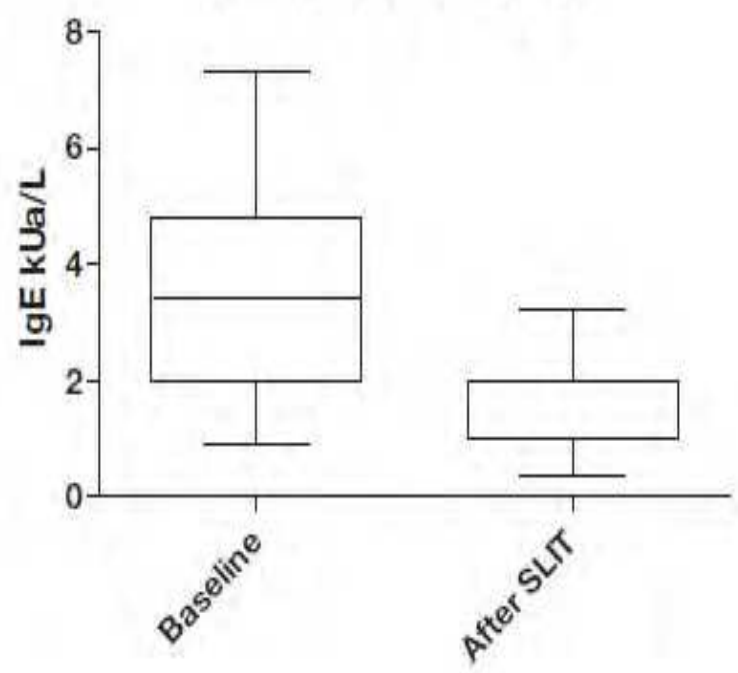

Fig. 2. Modification of specific anti HDM IgE serum levels at baseline and after1 year of SLIT treatment $(\mathrm{n}=96) ; \mathrm{p}=0.0001$ paired $\mathrm{t}$-test.

\section{Conclusion}

Atopic Dermatitis (AD) is a common inflammatory itching skin disease affectings a large number of children and adults. Symptoms commonly could vary from person to person. The most common symptoms are dry, itchy skin and rashes on the face, inside the elbows and behind the knees, and on the hands and feet. Itching is the most relevant and common symptom of atopic dermatitis. Scratching and rubbing in response to itching irritates the skin, increases inflammation, and actually increases itchiness. The cause of atopic dermatitis is not known, but the disease seems to result from a combination of genetic and environmental factors. Children are more likely to develop this disorder if one or both parents have had it or have had other allergic conditions like asthma or allergic rhinitis. While some people outgrow skin symptoms, approximately three-fourths of children with atopic dermatitis go on to develop hay fever or asthma. AD frequently is associated with allergic respiratory disease and often is the first manifestation of allergic disease. Patients suffering from AD will develop allergic rhinitis and asthma. The inflammatory process in the skin of patients with AD initiates with the allergen uptake by epidermal dendritic cells which share in their surface the IgE-receptor. These cells, after the contact with the allergens, start the homing process of $\mathrm{T}$ cells. This process plays a 
central role for the inflammatory damage of skin. Up to $80 \%$ of patients suffering from AD are sensitised against different aero and food allergens. This sensitisation is reflected by an increased total and allergen-specific IgE and/or by a positive Skin prick test. So far not causative treatments are available for the treatment of AD. Topical corticosteroids and calcineurin inhibitors could ameliorate the clinical manifestation of AD. AD is frequently the first clinical manifestation of atopic disease in infancy. Basic therapy of AD comprises optimal skin care, emollient creams, topical corticosteroids and/or topical calcineurin inhibitors. Despite a strong rationale, hyposensitization with specific immunotherapy is not an established strategic treatment of AD. However, a recent study has shown that SCIT with HDM allergen extracts in adults AD patients with positive skin test toward HDM allergens is effective in reducing the SCORAD index and reducing, in the mean time, the need for topical corticosteroids. A wide clinical use of SCIT is, however, limited by the inconvenience and safety profile of this route of administration. A sublingual route has emerged as an effective alternative to subcutaneous immunotherapy. A recent trial, performed in children with $\mathrm{AD}$, has shown that SLIT with HDM extracts could be effective in mild and moderate disease. SIT could be an effective and causal treatment of atopic dermatitis in patients with aeroallergen sensitivity. SLIT can modulate the immuno-system in patients with AD and HDM sensitivity. Several clinical trials (both controlled or uncontrolled) have shown that SIT is able to reduce the SCORAD and to reduce the use of symptomatic topical products. In conclusion the data available from different trials suggest that SIT (both SCIT and SLIT) could be a relevant therapeutic option in the management of AD.

\section{Acknowledgment}

ALK-Abello supported this study by providing immunotherapy extract. MM is ALK Abellò employee.

\section{References}

[1] Adkis C, Akdis M, Bieber T. Diagnosis and treatment of atopic dermatitis in children and adults: European Academy of Allergology and Clinical Immunonology / American Academy of Allergy, Asthma and Immunology / PRACTALL consensus report. J Allergy Clin Immunol 2006;118:152-69

[2] Williams HC, Strachan DP. The natural history of childhood eczema: observation from British 1958 birth cohort study. Br J Dermatol 1998;139:834-9

[3] Illi S, von Mutius E. The natural course of atopic dermatitis from birth to age 7 years and the association with asthma. J Allergy Clin Immunol 2004;113:925-31

[4] Hanafin J, Raijka G. Diagnostic features of atopic dermatitis. Acta Derm Venereol Suppl 1980;92:44-7

[5] Anon. Severity scoring of atopic dermatitis: the SCORAD index. Consensus report of European Task Force on Atopic Dermatitis. Dermatology 1993;186:23-31

[6] Seidenari S, Giusti G. Objective assessment of the skin of children affected by atopic dermatitis: a study of $\mathrm{pH}$, capacitance and TEWL in eczematous and clinically uninvolved skin. Acta Derm Venereol 1996;75:429-33. 
[7] Boguniewicz M, Leung DYM. Atopic dermatitis. J Allergy Clin Immunol 2006; 117(suppl):S475-80.

[8] Leung DYM, Bhan AK, Schneeberger EE, Geha RS. Characterization of the mononuclear cell infiltrate in atopic dermatitis using monoclonal antibodies. J Allergy Clin Immunol 1983;71:47-56

[9] Leung DY, Boguniewicz M, Howell MD, Nomura I, Hamid QA. New insights into atopic dermatitis. J Clin Invest 2004;113:651-7.

[10] Novak N, Kraft S, Bieber T. IgE receptors. Curr Opin Immunol 2001;13:721-6.

[11] Novak N, Valenta R, Bohle B, et al. Fcepsilon RI engagement of Langerhans cell-like dendritic cells and inflammatory dendritic epidermal cell-like dendritic cells induces chemotactic signals and different T-cell phenotypes in vitro. J Allergy Clin Immunol 2004;113:949-57.

[12] Leung DY, Bieber T. Atopic dermatitis. Lancet 2003;361:151-60.

[13] Proksch E, Folster-Holst R, Jensen JM. Skin barrier function, epidermal proliferation and differentiation in eczema. J Dermatol Sci 2006;43:159-69.

[14] Hudson TJ. Skin barrier function and allergic risk. Nat Genet 2006;38:399-400.

[15] Cork MJ, Robinson DA, Vasilopoulos Y, et al. New perspectives on epidermal barrier dysfunction in atopic dermatitis: gene-environment interactions. J Allergy Clin Immunol 2006;118:3-21

[16] Williams H, Flohr C. How epidemiology has challenged 3 prevailing concepts about atopic dermatitis. J Allergy Clin Immunol 2006;118:209-13.

[17] Anonymous. Worldwide variation in prevalence of symptoms of asthma, allergic rhinoconjunctivitis, and atopic eczema: ISAAC. The International Study of Asthma and Allergies in Childhood (ISAAC) Steering Committee. Lancet 1998;351:1225-32.

[18] Hoffjan S, Epplen JT. The genetics of atopic dermatitis: recent findings and future options. J Mol Med 2005;83:682-92.

[19] Bradley M, Soderhall C, Luthman H, Wahlgren CF, Kockum I, Nordenskjold M. Susceptibility loci for atopic dermatitis on chromosomes 3, 13, 15, 17 and 18 in a Swedish population. HumMol Genet 2002;11:1539-48.

[20] Williams HC, Strachan DP. The natural history of childhood eczema: observations from the British 1958 birth cohort study. Br J Dermatol 1998;139:834-9.

[21] Gustafsson D, Sjoberg O, Foucard T. Development of allergies and asthma in infants and young children with atopic dermatitis - a prospective follow-up to 7 years of age. Allergy 2000;55:240-5.

[22] Novak N, Bieber T, Leung DY. Immune mechanisms leading to atopic dermatitis. $J$ Allergy Clin Immunol 2003;112(suppl):S128-39.

[23] Strachan DP. Hay fever, hygiene, and household size. BMJ 1989;299:1259-60.

[24] Purvis DJ, Thompson JM, Clark PM, Robinson E, Black PN, Wild CJ et al. Risk factors for atopic dermatitis in New Zealand children at 3.5 years of age. Br J Dermatol 2005;152:742-9.

[25] Ozkaya E. Adult-onset atopic dermatitis. J Am Acad Dermatol 2005;52:579-82. 
[26] Novak N, Kruse S, Potreck J, Weidinger S, Fimmers R, Bieber T. Single nucleotide polymorphisms of the IL18 gene are associated with atopic eczema. J Allergy Clin Immunol 2005;115:828-33.

[27] Adinoff AD. Atopic dermatitis and aeroallergen contact sensitivity. J Allergy Clin Immunol 1988;81:736-42

[28] Novak N, Valenta R, Bohle B, Laffer S, Haberstok J, Kraft S et al. Fcepsilon RI engagement of Langerhans cell-like dendritic cells and inflammatory dendritic epidermal cell-like dendritic cells induces chemotactic signals and different T-cell phenotypes in vitro. J Allergy Clin Immunol 2004;113:949-57.

[29] Scalabrin DM, Bavbek S, Perzanowski MS,.Use of specific IgE in assessing the relevance of fungal and dust mite allergens to atopic dermatitis: a comparison with asthmatic and non asthmatic control subjects. J Allergy Clin Immunol 1999;104: 1273-9.

[30] Maintz L, Novak N. Getting more and more complex: the pathophysiology of atopic eczema. Eur J Dermatol 2007; 17:267-283.

[31] Werfel T, Kapp A. Environmental and other major provocation factors in atopic dermatitis. Allergy 1998;53:731-9.

[32] Tan BB, Weald D, Strickland I, et al. Double-blind controlled trial of effect of house dust mite allergen avoidance on atopic dermatitis. Lancet 1996;347:15-8.

[33] Subramanyan K. Role of mild cleansing in the management of patient skin. Dermatol Ther 2004;17:26-34.

[34] Loden M. Role of topical emollients and moisturizers in the treatment of dry skin barrier disorders. Am J Clin Dermatol 2003;4:771-88

[35] McHenry PM, Williams HC, Bingham EA. Management of atopic eczema: Joint Workshop of the British Association of Dermatologists and the Research Unit of the Royal College of Physicians of London. BMJ 1995;310:843-7.

[36] Korting HC, Kerscher MJ, Schafer- Korting M. Topical glucocorticoids with improved benefit/risk ratio: do they exist? J Am Acad Dermatol 1992;27:87-92.

[37] Wahn U, Bos JD, Goodfield M, Caputo R, Papp K, Manjra A et al. Efficacy and safety of pimecrolimus cream in the longterm management of atopic dermatitis in children. Pediatrics 2002;110:e2.

[38] Mastrandrea F. The potential role of allergen-specific sublingual immunotherapy in atopic dermatitis. Am J Clin Dermatol 2004;5:281-94.

[39] Bousquet J. Sublingual immunotherapy: validated. Allergy 2006;61:5-6

[40] Novak N, Simon Atopic dermatitis - from new pathophysiologic insights to individualized therapy. Allergy. 2011 Mar 3. doi: 10.1111/j.1398-9995.2011.02571.x

[41] Bussmann C, Bockenhoff A, Henke H, et al. Does allergen-specific immunotherapy represent a therapeutic option for patients with atopic dermatitis? J Allergy Clin Immunol 2006; 118:1292-1298

[42] Werfel T, Breuer K, Rueff F, Przybilla B, Worm M, Grewe M et al. Usefulness of specific immunotherapy in patients with atopic dermatitis and allergic sensitization to house dust mites: a multicentre, randomized, dose-response study. Allergy 2006;61:202-5. 
[43] Pajno G, Caminiti L. Sublingual immunotherapy in mitesensitized children with atopic dermatitis: a randomized double blind, placebo-controlled study. J Allergy Clin Immunol 2007 120(1):164-70.

[44] Cadario G, Galluccio AG, Pezza M, Appino A, Milani M, Pecora S, Mastrandrea F Sublingual immunotherapy efficacy in patients with atopic dermatitis and house dust mites sensitivity: a prospective pilot study. Curr Med Res Opin. 2007 Oct;23(10):2503-6. 


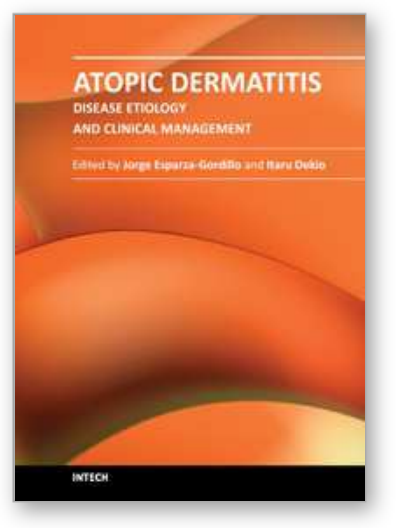

\author{
Atopic Dermatitis - Disease Etiology and Clinical Management \\ Edited by Dr. Jorge Esparza-Gordillo
}

ISBN 978-953-51-0110-9

Hard cover, 414 pages

Publisher InTech

Published online 22, February, 2012

Published in print edition February, 2012

Atopic Dermatitis is a common disease characterized by inflamed, itching and dry skin. This relapsing allergic disorder has complex etiology and shows a remarkably high clinical heterogeneity which complicates the diagnosis and clinical management. This book is divided into 4 sections. The first section (Disease Etiology) describes some of the physiological mechanisms underlying Atopic Dermatitis, including alterations in the immune system and the skin-barrier function. The important role of host-microorganism interactions on the pathophysiology of Atopic Dermatitis is discussed in the second section (Microorganisms in Atopic Dermatitis). An overview of the clinical diagnostic criteria and the disease management protocols commonly used is given in the third section (Diagnosis and Clinical Management). The last section (New Treatments) describes new therapeutic approaches that are not widely used but are currently being studied due to preliminary evidence showing a clinical benefit for Atopic Dermatitis.

\title{
How to reference
}

In order to correctly reference this scholarly work, feel free to copy and paste the following:

Massimo Milani (2012). Thinking Atopic Dermatitis Treatment Differently: Specific Immunotherapy as an Option, Atopic Dermatitis - Disease Etiology and Clinical Management, Dr. Jorge Esparza-Gordillo (Ed.), ISBN: 978-953-51-0110-9, InTech, Available from: http://www.intechopen.com/books/atopic-dermatitis-diseaseetiology-and-clinical-management/thinking-atopic-dermatitis-treatment-differently-specific-immunotherapy-asan-option

\section{INTECH}

open science | open minds

\section{InTech Europe}

University Campus STeP Ri

Slavka Krautzeka 83/A

51000 Rijeka, Croatia

Phone: +385 (51) 770447

Fax: +385 (51) 686166

www.intechopen.com

\section{InTech China}

Unit 405, Office Block, Hotel Equatorial Shanghai

No.65, Yan An Road (West), Shanghai, 200040, China

中国上海市延安西路65号上海国际贵都大饭店办公楼405单元

Phone: +86-21-62489820

Fax: $+86-21-62489821$ 
(C) 2012 The Author(s). Licensee IntechOpen. This is an open access article distributed under the terms of the Creative Commons Attribution 3.0 License, which permits unrestricted use, distribution, and reproduction in any medium, provided the original work is properly cited. 